\title{
Por que inexistem deveres absolutos de punir
}

\section{Luís Greco}

Professor Catedrático de Direito Penal, Direito Processual Penal, Direito Penal Estrangeiro e Teoria do Direito Penal na Universidade Humboldt, de Berlim, Alemanha

\section{SUMÁRIO}

I. Introdução

II. Considerações conceituais

III. Os argumentos em favor do dever absoluto de punir

1. As fontes do direito internacional

2. A obrigação de respeitar e garantir direitos humanos

3. O argumento adicional

4. Conclusão intermediária

IV. Os dois porquês de inexistir um dever absoluto de punir

1. Deveres-meio nunca são absolutos no sentido de incondicionados

2. Deveres de ação nunca são absolutos no sentido de cogentes

v. Conclusão 


\section{Introdução}

Verifica-se, no moderno Direito Penal internacional, amplo consenso sobre a existência de um dever de punir graves violações de direitos humanos. Não tão uniforme, mas bastante difundida é também uma opinião a respeito da qualidade desse dever: não se trataria de um dever condicionado, tampouco prima facie, e sim de um dever absoluto. Em nome desse dever absoluto caíram as barreiras da soberania e da prescrição; agora são criticados a anistia e os acordos de paz. O slogan em que se baseia essa crítica é a chamada luta contra a impunidade. Objeto de minhas reflexões serão esses afirmados deveres absolutos de punir; tentarei demonstrar por que eles inexistem.

Procederei em três etapas. Após estabelecer, numa breve primeira etapa, precisões conceituais (abaixo II.), ocupar-me-ei dos argumentos em favor de um dever absoluto de punir (abaixo III.). Aqui, demonstrarei que nenhum desses argumentos logra convencer. Numa terceira etapa, tentarei provar que nenhum argumento em favor de um absoluto de punir é sequer imaginável, já por razões que dizem respeito à estrutura dos deveres em questão (abaixo IV.).

\section{Considerações conceituais}

Parece-me aconselhável definir alguns conceitos de que recorrentemente me valerei nas presentes reflexões, cujo objeto é a existência de deveres absolutos de punir. Não definirei pena ${ }^{1}$, nem dever, mas tão-somente a qualidade de «absoluto» de um dever. Essa qualidade tem um duplo sentido: ela pode ser entendida, a uma, como contraposta à qualidade de «condicionado», e, a duas, como contraposta à qualidade de «prima facie» ou «derrotável» (defeasable).

A primeira contraposição - absoluto como contrário de condicionado - significa que defenderia um dever absoluto de punir quem entender que, sempre que ocorrer uma grave violação de direitos humanos, surgirá um dever de punir. Esse dever é incondicionado, no sentido de que a existência de uma grave violação de direitos humanos é condição suficiente para o surgimento do dever de punir. Um dever condicionado sequer surge se não se der a condição. Se ela, contudo, surge, nada mais é necessário para que se afirme o dever.

A segunda contraposição - absoluto como contrário de prima facie ou derrotável - se explica da seguinte forma. Prima facie ou derrotável (defeasable) é um dever que pode ser superado por considerações contrapostas. Absoluto

1 Sobre essa definição, extensamente, GRECO, Strafprozesstheorie und materielle Rechtskraft, 2015, pp. 640 e ss. 
ou cogente é, por sua vez, um dever impassível de superação por qualquer outra consideração. Enquanto o dever incondicionado sequer surge se não se der a condição, o dever prima facie surge, mas pode ser afastado por razões opostas.

Demonstrarei por que inexistem deveres absolutos de punir nesses dois sentidos apresentados.

\section{Os argumentos em favor do dever absoluto de punir}

Parto de premissa evidente para uma perspectiva liberal: a de que o dever de punir, como dever de impor um mal, de restringir liberdade, é uma grandeza carecedora de justificação. A liberdade se presume, a restrição de liberdade se justifica. Essa ideia está por trás de afirmações (um tanto vagas) como o favor libertatis ou o in dubio pro libertate. Pergunta-se, assim, de onde surge um dever de punir; são essas razões que podem sustentar a pretensão de um dever absoluto de punir nos dois sentidos acima descritos.

O caminho mais natural é buscar a existência de um dever absoluto de punir no direito internacional positivo, isto é, nas chamadas fontes do direito internacional. Se essa tentativa não for coroada de êxito, perguntar-se-á por uma fundamentação que supera os limites do direito positivo.

\section{As fontes do direito internacional}

As fontes do direito internacional são acordos internacionais, direito consuetidunário, princípios gerais de direito, jurisprudência e doutrina qualificada (art. 38 I, Estatuto da Corte Internacional de Justiça).

a) Uma passada em revista dos acordos internacionais revela, é verdade, vários deveres de punir. Mencionem-se, aqui, apenas os arts. 4 e ss da Convenção das Nações Unidas contra a Tortura; os arts. 4 e ss da Convenção das Nações Unidas contra o Genocídio; os arts. 49. e ss da Primeira Convenção de Genebra; os arts. 50 e ss da Segunda Convenção de Genebra; os arts. $129 .^{\circ}$ e ss da Terceira Convenção de Genebra; os arts. 146 e ss da Quarta Convenção de Genebra; o art. 3. ${ }^{\circ}$ da Convenção Interamericana sobre o Desaparecimento Forçado de Pessoas. Não parece, contudo, que de qualquer desses documentos se possa extrair a natureza absoluta dos deveres de punir ali previstos. Claro está que eles contêm deveres de punir; se absolutos, permanece em aberto.

Deveres absolutos de punir não se encontram nem mesmo no Estatuto do Tribunal Penal Internacional. Pelo contrário, esse diploma conhece uma série 
de dispositivos que preveem uma renúncia à pena por razões de oportunidade (arts. 16, $17|\mathrm{~d}, 53| \mathrm{c}, \| \mathrm{c})^{2}$.

b) $\bigcirc$ direito consuetudinário tampouco nos fornece um dever absoluto de punir. O pressuposto objetivo da existência de direito costumeiro, qual seja, a chamada longa consuetudo (ao lado do pressuposto subjetivo da opinio juris $)^{3}$, inexiste no que se refere a esses deveres, cujo não-cumprimento ainda parece ser a regra.

c) Poder-se-ia, em seguida, recorrer aos chamados princípios gerais de direito, que são algo próximo a uma opinio juris sem longa consuetudo ${ }^{4}$. Se for esse o caso, trata-se de argumento evidentemente circular: ele oferece como razão para aceitar algo a contingência de fato de que esse algo já é aceito. Além disso, essa contingência fática é empiricamente questionável, uma vez que não se enxerga um consenso a respeito de obrigação absoluta de punir.

d) As mesmas duas objeções são cabíveis diante de uma eventual tentativa de derivar um dever absoluto de punir da jurisprudência internacional ou de autores renomados.

\section{A obrigação de respeitar e garantir direitos humanos}

Teremos de ir além das tradicionais fontes do direito internacional. Um possível caminho oferece, aqui, a Corte Interamericana de Direitos Humanos ${ }^{5}$. Essa Corte derivou do dever de respeitar e assegurar direitos humanos previstos no art. 1. I da Convenção Americana de Direitos Humanos a consequência de que violações de direitos humanos não podem permanecer impunes ${ }^{6}$. $\mathrm{dever}$ referido aos direitos humanos previsto no direito internacional conteria o ulterior dever de punir as graves violações a direitos humanos.

2 No mesmo sentido, Ferdinandusse, Direct Application of International Criminal Law in National Courts, The Hague/Cambridge, 2006, p. 201 - sobre esses dispositivos em mais detalhe RoHER, Legalitäts- oder Opportunitätsprinzip beim Internationalen Strafgerichtshof, 2010, pp. 109 e ss.

3 Por todos, Verdross/Simma, Universelles Völkerrecht, 3. ${ }^{a}$ ed., 1984, 349 e ss, 353 e ss.

$4 \quad$ Nesse sentido, Ambos Straflosigkeit von Menschenrechtsverletzungen, 1997, pp. 183 e ss, 203 e s.

5 Cf. a própria síntese da Corte na decisão Gelman vs. Uruguay de 24.2.2011, §§ 225 e ss, http://www. corteidh.or.cr/docs/casos/articulos/ seriec_221_esp1.pdf. Na literatura cf. CASSEL, Law \& Contemporary Problems 59 (1996), p. 208 e ss; GAvRon, International and Comparative Law Quarterly 51 (2002), pp. 91 e ss (95 e ss); Tomuschat, Festschrift für Steinberger, 2002, pp. 316 e ss (321 e s).

6 Pioneira a decisão Velásquez Rodríguez vs. Honduras de 29.7.1988, §§ 166, 174 e ss, http://www. corteidh.or.cr/docs/casos/articulos/seriec_04_ing.pdf; a respeito, extensamente, RoHT-ARRIAZA, California Law Review (= CalLR) 78 (1990), pp. 449 e ss (467 ss); de acordo AmBos, Archiv des Völkerrechts 37 (1999), pp. 318 e ss (319 e ss, 327 e s); acertada crítica em TomUschAT (Fn. 6), p. 321 («excessive rigour»). 
Essa fundamentação é, contudo, carecedora de precisão. Afinal, não se enxerga, num primeiro momento, de que maneira o segundo dever possa derivar do primeiro ou mesmo ser parte dele. De onde deriva o dever de punir, uma vez que já concluída a violação a direito humano?

O argumento mais preciso pode ser construído em duas etapas. A primeira delas é o caráter obrigatório dos direitos humanos. Uma vez reconhecido que esses direitos obrigam os Estados, faz-se necessário esclarecer que obrigações, exatamente, aqui se produzem. A distinção que aqui mais importa parece ser aquela entre deveres negativos, de omitir violações de direitos humanos, e deveres positivos, cujo conteúdo é a realização de uma conduta no sentido da proteção desses direitos ${ }^{7}$. É a ela que se refere a Convenção, quando usa, em seu art. $1 .{ }^{\circ}$, os termos «respeitar» (dimensão negativa, dever de omitir, de não lesionar) e «assegurar» (dimensão positiva, dever de atuar, de proteger) - no que segue, aliás, uma difundida terminologia em documentos de proteção de direitos individuais ${ }^{8}$.

Cumpre, num segundo passo, percorrer o caminho desse dever de respeitar e proteger direitos humanos até o dever de punir ${ }^{9}$. O dever de punir é um dever de atuar, um dever positivo; ele não se cumpre pela mera inação. Ele só pode, assim, derivar da dimensão positiva do dever relativo aos direitos humanos, do dever de proteger, e não do dever de respeitar ${ }^{10}$. Nesse ponto surge uma dificuldade: a rigor, a não punição não viola qualquer direito humano, uma vez que a violação se encontra no passado e foi cometida pelo delinquente ${ }^{11}$.

7 Na literatura de direito internacional BuERGENTHAL, in: Henkin (coord.), International Bill of Rights, New York, 1981, pp. 72 e ss (77 e s); Tomuschat (Fn. 6), pp. 316 e s; Ress, Kokot,, Mavrommatis e Klein, in: Klein (coord.), The Duty to Protect and to Ensure Human Rights, Berlin, 2000, pp. 165 e ss, 235 e ss, 277 e ss, 295 e ss; na literatura de direito constitucional GRAßHOF e SACHS, ambos no citado livro de Klein, pp. 33 e ss, 53 e ss; ISENSEE, in: Isensee/Kirchhof (coords.), Handbuch des Staatsrechts der BRD, vol. IX, 3. ${ }^{a}$ ed. 2011, $\S 191 \mathrm{~nm}$. 1 e ss; todos com ulteriores referências.

8 Cf. art. 2. I do Pacto Internacional de Direitos Civis e Políticos; art. 1 segunda frase da Carta de Direitos Fundamentais da União Europeia (referindo-se à dignidade humana); art. 1 I segunda frase da Lei Fundamental alemã (também referindo-se à dignidade humana).

9 A Corte Interamericana, contudo, não faz esse esforço de precisão, e sim deduz dever de punir diretamente da importância do direito humano e/ou da gravidade de sua violação. A diferenciada discussão sobre deveres constitucionais de proteção (BVerfGE 46, 160, 164 f.; 115, 118, 160; ISENSEE [nota 8] nm. 217 e ss, 295), para a qual a postulação de um dever de a uma concreta atuação protetiva permanece algo excecional, e sobre os deveres constitucionais de punir (referências em Roxin, Strafrecht Allgemeiner Teil, 4. ${ }^{a}$ ed., 2006, § 2 nm. 96), que sempre leva em conta o princípio da ultima ratio-Grundsatz, deveria receber maior atenção no Direito Penal internacional (entre as poucas exceções a quem não se dirige esta crítica encontra-se Seibert-Fohr, Prosecuting Serious Human Rights Violations, Oxford, 2009, pp. 211 e s).

10 No mesmo sentido Tomuschat (nota 6), pp. 317 e ss; Seibert-Fohr (nota 10), pp. 198 e ss; ao que parece também Corte Interamericana, Velásquez Rodríguez vs. Honduras (Fn. 7), § 172.

11 A não ser que se eleve o suposto direito da vítima à punição do autor, que encontra cada vez mais defensores (referências abaixo, nota 20) e ao qual já retornaremos (abaixo 3.c]), a um direito humano - uma construção, que aqui não podemos discutir. É manifesta, contudo, a tensa relação dessas ideias com as 
Não se trata, assim, de proteger o direito humano lesionado pelo delinquente, uma vez que a pena não desfaz o passado ${ }^{12}$. A não punição pode ser um cumprimento insuficiente do dever de proteger direitos humanos para o futuro, de prevenir lesões a direitos humanos ainda não ocorridas ${ }^{13}$. Não é, assim, a pessoa cujo direito foi criminosamente violado quem se quer proteger pela punição, e um número indeterminado de detentores do mesmo direito, o qual ficaria desprotegido na ausência de punição.

Ainda que se conceda que, com essa fundamentação, se fundamente de forma convincente um dever de punir, não parece claro se esse dever é condicionado/prima facie ou incondicionado/cogente. Para obter a um dever absoluto nesse duplo sentido da palavra é necessário um argumento adicional, em cuja busca agora saíremos.

\section{0 argumento adicional}

\section{a) lus cogens / obrigações erga omnes}

As figuras do ius cogens ou das obrigações erga omnes, a que a doutrina frequentemente se refere no presente contexto ${ }^{14}$, fornecem uma paráfrase de um dever absoluto de punir na linguagem do direito internacional, e não uma fundamentação ${ }^{15}$. Fica ainda em aberto por que o dever de punir representa ius cogens ou tem a qualidade de erga omnes.

premissas do Direito Penal liberal (e talvez mesmo do direito internacional liberal, cf. SEIBERT-FoHr [nota 10], pp. 207 e ss), segundo as quais a pena é sempre problemática e carecedora de justificação, uma vez que a ideia desloca o ônus de justificação para aquele que é contrário à pena.

12 Cf. já Welzel, Das deutsche Strafrecht, 11. ${ }^{\text {a }}$ ed. 1969, p. 3: o Direito Penal chegaria «muito tarde». Outra conclusão seria imaginável no máximo a partir de uma teoria retributivista da pena (defendida, para o Direito Penal internacional, por Lagodny, ZStW 113 [2001], pp. 800 e ss [806]; GIERHAKE, Begründung des Völkerrechts auf der Grundlage der Kantischen Rechtslehre, 2005, pp. 168 e ss; IDEM, Zur Legitimation des Völkerstrafrechts, ZIS 2008, 354 e ss; em parte WERLE/JESSBERGER, Völkerstrafrecht, 4. ${ }^{a}$ ed. 2011, nm. 117), uma teoria contudo, que implode a distinção entre não lesionar e proteger. A teoria da retribuição é de rechaçar-se, pelas conhecidas razões que se aduzem na discussão mais geral sobre os fundamentos do Direito Penal (cf., por todos, Roxin [nota 10], $§ 3 \mathrm{~nm} .8$ e ss.; minhas críticas encontram-se, principalmente, em GrECO, in: Estudos em homenagem a Tavares, Madrid/São Paulo, 2012, pp. 263 e ss).

13 De que forma essa prevenção deveria ocorrer, seria de determinar-se em um terceiro passo argumentativo, fundado pela teoria preventivo-geral que se defenda.

14 Bassioun, Law \& Contemporary Problems 59 (1996), pp. 9 e ss (17 e s); CASSESSE, European Journal of International Law 9 (1998), pp. 2 e ss (6); EL Zeidy, Michigan Journal of International Law 23 (2002), pp. 940 e ss (947 e ss); Della Morte, in: Fabri et alii. (coords.), La clémence saisie par le droit. Amnistie, prescription et grâce en droit international et comparé, Paris, 2007, pp. 39 e ss (74 e s); NTouband, Amnesty for Crimes Against Humanity under International Law, Leiden/Boston, 2007, pp. 217, 218 e ss; Tribunal Internacional para a Ex-lugoslávia, Prosecutor v. Furundzija, Case No. IT-95-17/1 v. 10.12.1998, §§ 153 e ss, 155.

15 Mesma conclusão em Tomuschat (Fn. 6), S. 342; PAStor, in: Libro Homenaje a Julio Maier, Buenos Aires, 2005, p. 699 e ss (p. 711 nota 61); NAQVI, Impediments to Exercising Jurisdiction over International Crimes, Den Haag, 2010, p. 143. 


\section{b) Direito à memória ou à verdade}

Um direito (das vítimas ou da sociedade) à verdade ${ }^{16}$ não conduz nem mesmo a um dever incondicionado de punir (uma vez que o processo penal não é nem de longe o melhor meio de descobrir a verdade histórica ${ }^{17}$ ), muito menos a um dever absoluto.

\section{c) Direito das vítimas à punição do autor}

Reportar-se a um suposto direito da vítima à punição do criminoso ${ }^{18}$ é uma estratégia duvidosa, a uma porque a existência desse direito não é nada eviden$t^{19}$, a duas porque não se enxerga de que modo ele seja capaz de fundamentar um dever absoluto de punir ${ }^{20}$.

\section{d) Combate à impunidade}

Poder-se-ia recorrer ao grande coringa do Direito Penal internacional, a que já nos referimos inicialmente: o combate à impunidade ${ }^{21}$. A palavra impunidade, entretanto, é vazia de conteúdo22. Impunidade não é mera ausência de pena, e sim ausência de pena lá onde a pena deve ser imposta. Noutras palavras, impunidade é o descumprimento de um dever de punir. Não é possível, assim, fundamentar um dever de punir, muito menos um dever absoluto, reportando-se ao combate à impunidade, porque isso seria uma petitio principii.

16 Por ex., Corte Interamericana de Direitos Humanos, Barrios Altos vs. Peru v. 14.3.2001, §§ 41 e ss, http://www.corteidh.or.cr/docs/casos/articulos/Seriec_75_esp.pdf; Almonacid Arellano u.a. vs. Chile u.a. v. 26.9.2006, §§ 86 e ss, http://www.corteidh.or.cr/ docs/casos/articulos/seriec_154_ing.pdf., $\S \S 148$ e SS.

17 Extensamente PAstor, Festschrift für Volk, 2009, pp. 541 e ss; cf. também Silva Sánchez, Pace Law Review 28 (2008), pp. 865 e ss (873); DAmASKA, in: Cassesse (coord.), Oxford Companion to International Criminal Justice, Oxford, 2009, pp. 175 e ss (180).

18 Por ex., Corte Interamericana de Direitos Humanos, Almonacid (nota 17), § 150; Stye, Virginia Journal of International Law 43 (2002), pp. 173 e ss (192, 201).

19 Em favor desse direito Reemtsma, Das Recht des Opfers auf Bestrafung des Täters - als Problem, 1999, pp. 26 e s; HöRnLE, JZ 2006, pp. 950 e ss; WeIGENd, RW 2010, pp. 39 e ss (51 e ss); críticos Silva Sánchez, Pace Law Review 28 (2008), p. 877; Seibert-Fohr (nota 10), pp. 206, 223; e Pastor (nota 16), pp. 706 e s.

20 Recordem-se, aqui, as concepções de Biggar, Ethical Theory and Moral Practice 5 (2002), pp. 167 e ss, que enxerga na satisfação da vítima («vindication») o principal fim da justiça penal, o qual poderia ser atingido também por uma renúncia tanto individual, quanto generalizada à pena; BıümmEL, Der Opferaspekt bei der strafrechtlichen Vergangenheitsbewältigung, 2002, pp. 274 e ss, 277, que apenas se posiciona contra uma excessiva generosidade; e Maluinder, Amnesty, Human Rights and Political Transitions, Oxford/ Portland, 2008, pp. 355 e ss, 376 e ss.

21 Por todos El ZeIDY, Michigan Journal of International Law 23 (2002), pp. 943, 946 e ss. Sobre o conceito de impunidade Ambos (nota 5), pp. 7 e ss.

22 Assim também Silva Sánchez, Pace Law Review 28 (2008), p. 872. 
e) Teorias da pena

Se se fizer o esforço de preencher a vazia ideia de impunidade com o conteúdo fornecido pelas teorias da pena, poder-se-ia até derivar um dever de punir a partir de razões de intimidação geral ${ }^{23}$, de reafirmação dos valores dos direitos humanos violados ${ }^{24}$ ou mesmo da justiça. Nenhuma dessas teorias da pena - pouco importa qual se considera correta ${ }^{25}$ - chega, contudo, a um dever absoluto de castigar. As duas primeiras perseguem fins terrenos, de maneira que recorrem dados empíricos que sempre possuem natureza contingente; ademais, nenhum dos tradicionais defensores da ideia de pena como imperativo de justiça defende deveres de punir pereat mundus ${ }^{26}$.

\section{Conclusão intermediária}

Chega-se, assim, a uma conclusão intermediária, que fecha a primeira parte do argumento do presente artigo. Não existe argumento a sustentar um dever absoluto de punir. No máximo, conseguiu-se fundamentar um dever condicionado e prima facie de punir.

\section{Os dois porquês de inexistir um dever absoluto de punir}

O argumento até agora desenvolvido teve caráter que se poderia chamar de falsificacionista, no sentido de que ele examinou, uma por uma, possíveis fundamentações para o afirmado dever absoluto de punir, e demonstrou por que cada uma delas falha. Demonstrou-se, assim, que falta uma fundamentação. Esse argumento de falsificação tem um limite natural: seu alcance é restrito às fundamentações examinadas (e às que delas logicamente decorrem). Ele não exclui que se formule uma fundamentação ulterior.

23 Nesse sentido Roht-ArriazA, CallR 78 (1990), p. 509; Seenyonjo, ICLR 7 (2007), p. 381.

24 SANCINETTI, Derechos humanos en Argentina post-dictatorial, Buenos Aires, 1988, pp. 8 e ss; IDEM, in: Libro Homenaje a Bacigalupo, Madrid/Barcelona, 2004, pp. 811 e ss (814 e s); MARKEL, University of Toronto Law Journal 49 (1999), pp. 389 e ss (p. 392), que fala em um «expressivismo social»; substancialmente também Sadat, Notre Dame Law Review 81 (2006), pp. 955 e ss.

25 Minha posição nessa controvérsia em GRECo, Lo vivo y lo muerto en la teoría de la pena de Feuerbach, trad. Dropulich/Béguelin, Madrid/São Paulo, 2015, pp. 276 e ss.

26 No meu "exemplo da ilha2", em que a punição do culpado lançaria a ilha de Kant em uma guerra civil, que teria por consequência a dissolução da sociedade (GRECO [nota 26], p. 234), nem mesmo KANT castigaria, uma vez que ele considera legítimo que se deixe de executar pena de morte quando há tantos criminosos envolvidos que a execução da pena acabaria com a existência do Estado (Metaphysik der Sitten, in: Weischedel [coord.], Werke, vol. VIII, 1993, pp. 307 e ss [primeira publicação: 1797], A 201/B 231). 
Pretendo, na parte final do trabalho em que agora adentro, demonstrar que tampouco faz sentido seguir em busca dessa fundamentação ulterior. Tentarei, aqui, não mais proceder a uma falsificação de posições já defendidas, e sim a uma prova negativa, a uma prova da inexistência do dever absoluto de punir. Essa prova se baseará em dois argumentos: o primeiro deles demonstrará o porquê da inexistência de deveres absolutos no sentido de incondicionados; o segundo terá por objeto o absoluto no sentido de cogente.

\section{Deveres meio nunca são absolutos no sentido de incondicionados}

Se o fundamento do dever de punir é o dever de proteger direitos humanos (acima III. 2.), esta proteção tem a natureza de um fim que se almeja, para o qual a punição representa um meio. Torna-se, portanto, uma questão empírica se esse meio é o mais indicado, e é impossível excluir de antemão a existência de outros meios mais adequados.

O que importa, assim, será se o Estado consegue ou não cumprir o seu dever de proteger ativamente os direitos humanos sem o Direito Penal. Um dever de punir apenas surgirá quando esses meios alternativos forem insuficientes. O fato de que os direitos humanos obriguem o Estado a uma proteção ativa não significa que essa proteção tenha de dar-se apenas pelo Direito Penal ${ }^{27}$.

Isso significa, concretamente, que sequer surgirá um dever de punir se o estado dispuser de uma satisfatória estratégia de proteção alternativa (no sentido de não penal). Não me parece possível, na presente sede, formular as exigências a que uma tal estratégia teria de atender. Limitar-me-ei a algumas considerações mais genéricas. Uma exigência clara e inafastável é a de que, se tal ainda não for o caso, se institucionalize um Estado de Direito, isto é, um Estado cujo poder é limitado pelo reconhecimento de direitos individuais ${ }^{28}$. Isso porque a existência de um Estado de Direito é pressuposto institucional de que os direitos humanos não fiquem abandonados a ulteriores violações. Ainda que eu não possa aqui estender-me sobre as demais exigências a que tem de atender essa estratégia de proteção não penal, não há porque excluir que elas possam ser cumpridas por um sancionamento extra penal ${ }^{29}$, ou mesmo por vias não sancionatórias, como pelo estabelecimento de uma comissão de verdade ou

27 Assim também GüNTHER, in: Beulke et alii (coords.), Das Dilemma des rechtsstaatlichen Strafrechts, 2009, pp. 79 e ss (98).

28 Se o conceito de Estado de Direito deve ou não ser enriquecido com ulteriores elementos, como com o reconhecimento de direitos sociais ou políticos, pode aqui ficar em aberto.

29 Sobre as possibilidades cf. WERLE, in: Muñoz Conde/Normbaum (coords.), Transformation von Diktaturen in Demokratien und Aufarbeitung der Vergangenheit, 2010, pp. 15 e ss (21). 
por medidas de reparação ${ }^{30}$. É importante, contudo, que elas funcionem, isto é, representem proteção igual à que seria de esperar-se do Direito Penal.

Se o presente acordo de paz colombiano é uma medida satisfatória, não cumpre a mim avaliar; se isso puder ser afirmado, haverá que admitir que o fim de proteção de direitos humanos estará assegurado, de modo que o dever de punir, dever-meio, sequer chegaria a surgir.

\section{Deveres de ação nunca são absolutos no sentido de cogentes}

O dever de punir é, além de um dever-meio, um dever positivo, um dever de atuar. Deveres de atuar só podem ser absolutos numa única situação, que dificilmente se verificará na realidade: na situação em que o sujeito obrigado não se encontra obrigado por nenhum outro dever de força igual ou superior ${ }^{31}$. Se o sujeito tiver também deveres adicionais, não se poderá excluir a possibilidade de uma colisão entre esses deveres, de maneira que um deles tenha de ceder. Apenas deveres negativos, de omissão, são imagináveis como deveres cogentes, uma vez que o seu cumprimento depende apenas de que o sujeito obrigado nada faça. Uma colisão de dever de omitir com outro dever de omitir é inimaginável ${ }^{32}$.

A punição é um atuar positivo. Os Estados contemporâneos estão subordinados não apenas a um dever de punir, como também a uma série de outros deveres de atuar e de omitir, como o dever de promover e de não pôr em risco a paz, o Estado de Direito, os direitos humanos etc. Ou seja, não se pode excluir uma colisão entre esses deveres. O dever de punir como dever cogente é, portanto, impensável, porque se trata de um dever de atuar, dirigido a um sujeito que está adstrito a vários outros deveres, de atuar e de omitir.

Querer defender o contrário reportando-se à natureza «absoluta» no sentido de resistente a considerações de emergência ou de necessidade de determi-

30 Sobre essa problemática em profundidade PLESsis/Peté (coords.), Repairing the Past?, Antwerpen/ /Oxford, 2007; de forma breve Werle (nota 30), p. 20.

31 GRECO (nota 25), pp. 120 e ss. Trata-se, assim, dos mesmos princípios com base nos quais se resolvem as chamadas colisões de deveres no Direito Penal (cf. Roxin, AT | 4. ${ }^{a}$ ed. 2006, § $16 \mathrm{~nm} .115$ e ss) e no direito constitucional (WAHL/MASING JZ 1990, pp. 553 e ss [559]; BVerfGE 115, 118, 160) que, por sua vez, derivam de uma filosofia moral não exclusivamente consequencialista, isto é, voltada à maximização de bens (cf. ademais Oderberg, Moral Theory: A Non-Consequentialist Approach, Malden, 2000, pp. 130 e ss).

32 Reconheço que isso é controvertido; em sentido contrário pioneiramente HRUSCHKA, Festschrift für Larenz, 1983, pp. 257 e ss (261 e s); contra também Neumann, in: Festschrift für Roxin, 2001, pp. 421 e ss (430). Não é possível, aqui, tomar posição sobre essa tese de que deveres de omissão também podem colidir; uma réplica convincente encontra-se em T. ZIMMERMANN, Rettungstötungen, 2009, pp. 205 e ss, com muitas ulteriores referências às pp. 187 e ss. 
nados direitos humanos (por ex., art. 27 II da Convenção Americana de Direitos Humanos; art. 2 II da Convenção contra a Tortura; art. 4 II do Pacto Internacional de Direitos Civis e Políticos; art. 15 II da Convenção Europeia de Direitos Humanos) ${ }^{33}$ tampouco é suficiente, porque essa pretensão de vigência absoluta só faz sentido no que diz respeito ao dever de omitir derivado do direito humano em questão, e não ao dever de atuar ${ }^{34}$.

Em que situações o dever de punir em si existente é derrotado por outros deveres tampouco posso especificar na presente sede. Limito-me, aqui, a mencionar que, se o dever de punir deriva do dever de proteger direitos humanos, o dever contrário deve ter hierarquia comparável. Se direitos são trunfos que prevalecem sobre considerações de bem comum ou dos interesses da maioria ${ }^{35}$, os deveres contrários não podem fundar-se apenas em considerações dessa ordem, e sim também no respeito e asseguramento de direitos humanos. Não será possível, assim, deixar de castigar por razões referidas à soberania nacional ou à democracia. A paz social será um argumento, desde que ela não seja entendida como ausência de discussão, e sim como situação em que não ocorrem violações sistemáticas de direitos humanos. Argumentos importantes serão, principalmente, o dever de não violar os direitos humanos dos suspeitos dessas violações, e o dever de não perpetuar uma situação de conflito que represente perigos para os direitos humanos, ou de não impedir ou fragilizar a institucionalização do Estado de Direito ${ }^{36}$. Para maiores detalhes, reporto-me a meu estudo sobre a permissibilidade de anistias no Direito Penal internacional, em que as ideias aqui apresentadas de forma mais abstrata são desenvolvidas diante de um exemplo concreto ${ }^{37}$.

33 Como parece fazer RoHT-ARRIAZA CallR 78 (1990), p. 487: «A necessary corollary of the nonderogability of such rights is that the actions are always subject to sanction and remedy»; em tendência também OrentLicher, YLJ 100 (1991), p. 2607 e ss.

34 Não se deve fazer nenhuma concessão a essa cogência dos deveres em questão (cf., com base no exemplo da tortura em situações de bomba-relógio, GRECO, in: Tortura, incesto y drogas: reflexiones sobre los límites del derecho penal, trad. Riggi, Buenos Aires, 2014, pp. 16 e ss); essa pretensão de cogência se dirige, contudo, apenas ao dever negativo, que impõe uma omissão, não, porém, a deveres positivos de proteção (a opinião dominante é aqui ainda pouco diferenciada, cf. por todos BuERGENTHAL, in: Henkin (coord.), International Bill of Rights, New York, 1981, pp. 72 e ss (83 e s); em detalhe MasLaton, Notstandsklauseln im regionalen Menschenrechtsschutz, 2002, pp. 77 e ss, 100 e s.

35 Pioneiramente Dworkin, Rights as Trumps, in: Waldron (coord.), Theories of Rights, 1984, pp. 153 e ss.

36 Bastante próximo NINo, YLJ 100 (1991), pp. 2619 e ss (2638 e ss); MAY, Crimes Against Humanity, Cambridge, 2005, p. 245; DENCKER, ZIS 2008, pp. 298 e ss (302 e s), que acertadamente releva que nem sempre se tratará de um conflito entre direitos humanos e política, mas muitas vezes de direitos humanos entre si.

37 Greco, GA 2012, pp. 670 e ss. 


\section{Conclusão}

Não há deveres absolutos de punir. Há, sim, um dever de punir, derivado do dever mais geral de proteger direitos humanos. Esse dever, contudo, não tem natureza incondicionada e cogente. Primeiramente, não se encontra qualquer fundamentação para tanto. Em segundo lugar e de forma mais fundamental, esse fundamento é impossível, porque um dever de punir derivado de um dever de proteger tem a natureza de dever-meio e de dever de atuação positiva. Ocorre que um dever-meio nunca pode ser incondicionado, e um dever de ação só poderá ser cogente se for o único dever a que o sujeito se encontra vinculado.

Quem se reporta a direitos humanos para defender uma obrigação absoluta de punir está, em verdade, preocupado não mais com direitos de pessoas concretas que cumpre proteger, e sim mostrando-se disposto a sacrificar esses direitos e essas pessoas em nome de uma suposta ideia de direitos humanos desvinculada de seus reais titulares. O direito internacional e o direito penal dos direitos humanos têm de ser, antes de qualquer outra coisa, direitos de proteção de seres humanos concretos. 